\title{
Are There Any Differences in the Work Experiences of Local and Rural-to-Urban Migrant Female Factory Workers? An Exploratory Study in Guangzhou, China
}

\author{
Siu-Ming To
}

\begin{abstract}
This study compared the perceived job rewards, job satisfaction, and organizational commitment of local and rural-to-urban migrant female factory workers in Guangzhou, China. This research used a cross-sectional quantitative survey and systematic random sampling for data collection at two toy factories in Guangzhou. Research participants voluntarily and anonymously completed a structured questionnaire. Based on the final sample of 1,307 female workers, the results indicated significant differences in the perceived job rewards between locals and migrants after ruling out the effect of age. Specifically, migrant female workers felt more content with all types of job rewards when compared to local female workers. The results suggest that the work experiences of Chinese female factory workers are influenced by the rural-urban stratification. Overall, these findings may assist policy makers and companies in improving the work and lives of female factory workers.
\end{abstract}

Index Terms-Female factory workers, job rewards, job satisfaction, organizational commitment.

\section{INTRODUCTION}

Since the early 1980s, the blooming economy in China has helped fuel the migration of the rural workforce to urban cities. In 2017, approximately 137 million rural migrant workers relocated to urban cities in China, where $31.3 \%$ of this group was female [1]. Most tend to settle in the southern and eastern coastal areas of China, also known as the centres of Chinese economic development. The Guangdong province is one of such areas and has attracted many domestic migrants seeking job opportunities. In 2011, the total urban workforce in Guangdong was about 12.4 million individuals [2]. Roughly $40.8 \%$ (5.1 million) of them were females and about $47 \%$ (2.4 million) were employed in the manufacturing sector [3]. Most of these female laborers worked in toy, electronic, and garment manufacturing factories [4].

Not surprisingly, such a massive number of off-farm migrant workers in China has drawn much attention from researchers, particularly to the demographic trends and economic impacts of rural-to-urban migrant workers. Because of their hukou (household registration) status as rural residents, migrant workers are not allowed to enjoy the same employment, working conditions, social security, medical benefits, or subsidized housing as the urban residents in the

Manuscript received March 9, 2019; revised May 12, 2019. This work was financially supported by the South China Programme Research Grant of the Hong Kong Institute of Asia-Pacific Studies, The Chinese University of Hong Kong.

S. M. To is with The Chinese University of Hong Kong, HK (e-mail: siumingto@cuhk.edu.hk). cities can [5]. For example, most migrant workers take up the low-status jobs that urban residents refuse to do [6]. They also have longer working hours than urban residents and they seldom receive social security [7], seldom have medical benefits [8], and live in poor conditions [9]. In recent years, researchers have also decided to place their focus on how the migrant workers' socially disadvantaged position influences them psychologically. For example, Mou and colleagues found that $21.4 \%$ of migrant factory workers in Shenzhen showed depressive symptoms [10], and Wong and Leung found that migration stress adversely affected the mental health of male and female migrant workers in Shanghai [11].

Patriarchy permeates the Chinese society in that women, especially those from rural areas, tend to be deprived of basic rights and opportunities for self-development [12]. Women are expected to marry at an early age and to stay home to perform household and childcare duties. There is little social concern about whether these women truly want to follow these cultural norms. As a result, obtaining employment in urban areas can be seen as a way to liberate many Chinese women by allowing them to become independent and make their own choices [13], [14]. In contrast, women from urban cities tend to have higher expectations of the benefits and sense of satisfaction to be gained from their jobs [15]. As urban women tend to be more educated, they may feel entitled to better job rewards, which could lead to job dissatisfaction when these expectations are not being met [16]. With the increasing trend of rural-to-urban domestic migration, a deeper understanding of the experiences of female workers in China could assist in improving the work and personal lives of these individuals, especially migrant female workers. As such, this study aimed to explore the differences between local female workers and migrant female workers in terms of perceived job rewards, job satisfaction, and organizational commitment.

Job rewards include the financial and non-financial benefits obtained through one's employment [17]. According to Williamson and colleagues, the types of job rewards include: extrinsic rewards, which are the tangible benefits of a job such as pay, fringe benefits, and promotion; intrinsic rewards, which are the motivational characteristics of a job such as autonomy, role clarity, and training and development opportunities; and social rewards, which are the social relationships or support stemming from the employee's supervisors or coworkers [18]. Because the perceived value of job rewards largely depends on each individual, job rewards are subjectively construed and experienced [19]. Previous studies in China found that employees tend to rank 
salary and other extrinsic benefits as more important than intrinsic benefits [20], [21]. Also, as Chinese society values respect for seniors, social rewards such as interpersonal relationships between supervisors and subordinates - called guanxi in Chinese - are also highly important for Chinese employees [22]. However, research on female factory workers' perceived job rewards are lacking, thus studies in this area are much needed.

Job satisfaction is closely related to perceived job rewards, work values, work conditions, and individual attributes [23], [24]. It is described as one's affective feelings towards his or her work experiences [25]. Nielsen and colleagues argued that job satisfaction is important for both employees and organizations in China [26], since Chinese employees are more likely to resign [27] or be absent from work [28], [29] when they feel dissatisfied with their jobs.

However, the amount of research on job satisfaction in China does not match up to importance of this issue. Moreover, the extant studies tend to focus only on urban employees at the managerial level [30], [31], and research on non-managerial urban employees or even migrant workers are rare. In one of the few studies conducted on migrant workers, Chan and Qiu found that migrant workers are generally satisfied with their jobs despite long working hours and poor living and working conditions [32]. A possible explanation for this is that migrant workers can earn more than they would otherwise earn in their hometowns and can thus send remittances to support their families, hence contributing to feelings of job satisfaction. Similarly, Nielsen and colleagues compared the job satisfaction and subjective wellbeing of local urban workers and off-farm migrant workers in the Fujian province of China [26], and found that migrant workers with higher educational levels tend to report lower job satisfaction. Also, work environment seems to be predictive of job satisfaction, and working in a manufacturing or construction setting appeared to reduce job satisfaction. Furthermore, Nielsen and Smyth [33] found that men had higher job satisfaction than women in urban areas because women held higher expectations for work. Nonetheless, job satisfaction among female workers still remains underexplored.

Mowday and colleagues posited that organizational commitment is one's commitment to the employer [34]. The three kinds of organizational commitment include: affective commitment as a person's emotional attachment to, identification with, and involvement in the organization; continuance commitment as a person's continuance to work for the organization because of the financial implications of leaving; and normative commitment as the societal norm surrounding how one ought to remain loyal to the organization [17], [18]. Newman and Sheikh found that employees' extrinsic job rewards, satisfaction with supervision, and perceived role clarity were positively associated with affective organizational commitment [17]. In another study targeting Chinese migrant workers, Chan and Qiu found that there were no gender differences in organizational commitment, but older migrant workers tend to have a higher commitment to their organization compared to their younger counterparts [32]. However, there is still insufficient literature regarding the organizational commitment of Chinese female factory laborers. The present study therefore focuses on Chinese female factory workers' affective organizational commitment.

\section{METHOD}

\section{A. Sampling}

Two quantitative surveys were conducted in two toy factories in Guangzhou. Guangzhou is one of the most economically advanced cities in China and has the highest gross domestic product per capita within the Guangdong province [4]. In particular, the toy industry in the Guangdong province is responsible for manufacturing approximately $69.3 \%$ of toys in the world [35]. Given the prevalence of toy factory workers in Guangzhou, this group of workers is fairly representative of ordinary factory workers as a whole within the entire province. Overall, factory workers in Guangzhou are between the ages of 16 and 30, single, and can handle monotonous work and swift assembly work for 10 to 12 hours each day [4]. Moreover, their working life span can generally last for more than 20 years, until they are no longer able to tolerate such arduous physical labor.

Non-randomized sampling methods are commonly used in studies regarding Chinese migrant laborers (e.g. [26], [32]) because there are many restrictions surrounding random sampling methods [36]. For instance, companies are concerned about the company's image, compliance with the law, and employees' perceptions when they reflect on topics such as job satisfaction and expectations. As a result, systematic random sampling was used in this study, and both local and migrant workers of all ages were invited to participate in order to avoid suspicious labeling. Two quantitative surveys were conducted. Data was collected from 8,000 workers from two toy factories in two districts of Guangzhou. Then, every third worker from the name list of all production line workers was selected. Ultimately, only 1,307 female workers were included in this study. Furthermore, this study was able to benefit from the help of a Chinese consultancy firm that runs employee assistance programs for several factories in the Guangdong province.

\section{B. Measures}

Based on Mottaz' study [37], a scale of 15 evaluative statements utilizing the three dimensions of perceived job rewards was developed and validated [15]. The first subscale (6 items) is about extrinsic job rewards. The second subscale (6 items) is related to social job rewards. The third subscale (3 items) is about intrinsic job rewards. All 15 items are rated on a seven-point Likert-type scale from 1 (disagree very much) to 7 (agree very much). A higher total subscale score reflects a greater agreement with the acquisition of that job reward dimension. The reliability alpha coefficients of the three subscales $($ extrinsic $=.85$; social $=.81$; intrinsic $=.72)$ were all found to be satisfactory.

Kalleberg's five-item scale was adopted to measure each participant's overall job satisfaction [38]. Sample items include "How satisfied are you with your job" and "Would you take the same job again if a choice is given?" All five 
items are rated on a seven-point Likert-type scale from 1 (disagree very much) to 7 (agree very much). The total scores range from 5 to 35 . A higher total score reflects greater satisfaction with the job. The composite score of the five items yielded a reliability alpha coefficient of .72 .

To assess affective organizational commitment, participants were asked how long they would stay in the present company. The response categories were 1 (1-6 months), 2 (7-12 months), 3 (13-24 months), 4 (25-36 months) and 5 (37 months or beyond). The results indicate that organizational commitment was positively correlated with the full scale of perceived job rewards $(r=.26, p<.01)$ and job satisfaction $(r=.49, p<.000)$.

\section{Data Collection and Analysis}

Ethical approval for the study was obtained from the Survey and Behavioral Research Ethics Committee at The Chinese University of Hong Kong. With permission from factory managers, two trained data collectors held two instruction sessions per day to brief participants on the research purpose and to obtain informed written consents from each participant. Around 40 participants enrolled in each session, hence allowing all 1,307 final questionnaires to be completed within a month. Participants voluntarily and anonymously completed a structured questionnaire in a private conference room inside the factories. During the entire process, the data collectors heavily emphasized that the participants' identities would remain confidential and encouraged participants to respond to the survey items in accordance with their own personal thoughts.

The data collected was then analyzed using the statistical software PASW 17.0. Descriptive statistics were used to examine the socio-demographic information and to determine the mean value and standard deviation of each item. Multivariate analysis of variance (MANOVA) was used to compare the perceived job rewards, job satisfaction, and organizational commitment between local and migrant female workers. While recent research findings have shown profound intergenerational changes in work values and job expectations among migrant laborers in China [15], [39], [40], multivariate analysis of covariance (MANCOVA) was also used to test if the possible differences would remain after ruling out the effect of age.

\section{RESULTS}

Table I shows the socio-demographic characteristics of participants. Among the 1,307 participants, nearly half were migrant females and just over half were local females. Of the 596 migrant females, over half had lived in Guangdong for more than five years at the time of the survey, while one fourth had lived in the province for less than three years. Half of the total sample were between the ages of 29 and 40, and over $80 \%$ were married. These latter two figures were similar to those of the local respondents. Moreover, $21 \%$ migrant females received education at the elementary level or below, although most migrant and local females were educated at the middle school level. Despite the migrant females' lower education levels, their reported monthly salaries were slightly higher than that of their local counterparts because most of migrant females were willing to work overtime in order to earn more money.

TABLE I: SOCIO-DEMOGRAPHIC CHARACTERISTICS OF THE RESEARCH PARICIPANTS

\begin{tabular}{lll}
\hline \hline & Local & Migrant \\
\cline { 2 - 3 } Socio-demographic & $\begin{array}{l}\text { \% Percentage } \\
(n=621)\end{array}$ & $\begin{array}{l}\text { \% Percentage } \\
(n=596)\end{array}$ \\
\hline Lharacteristics & & \\
36 month of migration & N/A & 24.2 \\
37-60 months & N/A & 19.1 \\
61 months or above & N/A & 56.7 \\
Age group & & \\
17-28 & 29.8 & 22.7 \\
29-40 & 53.9 & 50.8 \\
41 or above & 16.3 & 26.5 \\
Marital status & & \\
Single & 16.5 & 11.7 \\
Married & 80.3 & 85.2 \\
Divorced/Widowed & 3.2 & 3.1 \\
Education level & & \\
Elementary or below & 7.9 & 21.0 \\
Middle school & 74.1 & 66.9 \\
High school or above & 18.0 & 12.1 \\
Monthly salary (RMB¥) & & \\
1,000-1,200 & 77.8 & 6.3 \\
1,201-1,400 & 13.8 & 26.5 \\
1,401-1,600 & 4.7 & \\
1,601-1,800 & 2.7 & \\
1,801-2,000 & 0.8 & \\
2,001 or above & 0.2 & \\
\hline \hline
\end{tabular}

In response to the main research question, the results indicate significant differences in the work experiences of local and migrant female workers, as demonstrated by a significant Wilks' Lambda effect (value $=.95, F=7.85, p$ $<.001, \eta^{2}=.05$ ). Specifically, migrant female workers felt more satisfied than their local counterparts with all three types of job rewards, and had more positive perceptions of their jobs. However, there were no significant differences in organizational commitment between migrant and local workers. Table II summarizes these results.

Furthermore, after ruling out the effect of age by treating it as a covariate, the results still indicate significant differences in the three types of job rewards of local and migrant female workers, as demonstrated by a significant Wilks' Lambda effect (value $=.96, F=6.01, p<.001, \eta^{2}=.04$ ). Nevertheless, there were no significant differences in both job satisfaction and organizational commitment between migrant and local workers. Table III summarizes these results.

\section{DISCUSSION, IMPLICATIONS, AND FUTURE RESEARCH DIRECTIONS}

There has been increasing research in recent years examining the demographic trends of and the social factors impacting the lives of female migrant workers. However, most of such research are focused on the social exclusion, economic deprivation, and other individual or social problems encountered by migrant workers [5], [10], [41]. The literature has largely neglected the subjective perceptions and 
experiences of workers. As a result, the present study sought to compare the possible differences in the perceived job rewards, job satisfaction, and organizational commitment of local and migrant female factory workers, in addition to investigating demographic backgrounds. Therefore, the findings from this study can create further dialogue about the current work experiences of migrant female workers within this region.

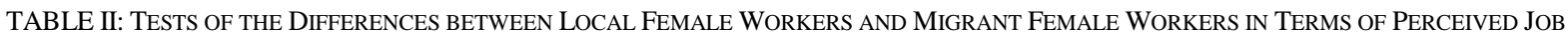
REWARDS, JOB SATISFACTION, AND ORGANIZATIONAL COMMITMENT

\begin{tabular}{|c|c|c|c|c|c|c|}
\hline \multirow[b]{2}{*}{ Variables } & \multirow{2}{*}{$\begin{array}{l}\text { Local }(\mathrm{n}=621) \\
\text { Mean }(\mathrm{SD})\end{array}$} & \multirow{2}{*}{$\begin{array}{l}\text { Migrant }(n=596) \\
\text { Mean }(\mathrm{SD})\end{array}$} & \multicolumn{3}{|c|}{ Statistical comparison } & \multirow[t]{2}{*}{$\begin{array}{l}\text { Pairwise comparisons based } \\
\text { on estimated marginal means }\end{array}$} \\
\hline & & & $F$ & $p$ & $n^{2}$ & \\
\hline \multicolumn{7}{|l|}{ Job Rewards } \\
\hline Extrinsic & $18.49(7.94)$ & $21.84(7.86)$ & 36.69 & 0.000 & 0.043 & Migrant > Local \\
\hline Social & $25.11(7.12)$ & $27.20(6.83)$ & 18.28 & 0.000 & 0.022 & Migrant > Local \\
\hline Intrinsic & $11.21(4.25)$ & $12.16(4.14)$ & 18.62 & 0.001 & 0.013 & Migrant > Local \\
\hline Job Satisfaction & $18.71(5.81)$ & $19.51(6.13)$ & 3.65 & 0.05 & 0.004 & Migrant > Local \\
\hline Organizational Commitment & $2.76(1.16)$ & $2.89(1.30)$ & 2.24 & 0.13 & 0.003 & No difference \\
\hline
\end{tabular}

TABLE III: TESTS OF THE DIFFERENCES BETWEEN LOCAL FEMALE WORKERS AND MIGRANT FEMALE WORKERS IN TERMS OF PERCEIVED JOB REWARDS, Job SATISFACTION, AND ORGANIZATIONAL COMMITMENT AFTER CONTROLLING THE EFFECT OF AGE

\begin{tabular}{|c|c|c|c|c|c|c|}
\hline \multirow[b]{2}{*}{ Variables } & \multirow{2}{*}{$\begin{array}{l}\text { Local }(\mathrm{n}=621) \\
\text { Mean }(\mathrm{SD})\end{array}$} & \multirow{2}{*}{$\begin{array}{l}\text { Migrant }(\mathrm{n}=596) \\
\text { Mean }(\mathrm{SD})\end{array}$} & \multicolumn{3}{|c|}{ Statistical comparison } & \multirow[t]{2}{*}{$\begin{array}{l}\text { Pairwise comparisons based } \\
\text { on estimated marginal means }\end{array}$} \\
\hline & & & $F$ & $p$ & $n^{2}$ & \\
\hline Extrinsic & $18.65(7.96)$ & $21.82(7.82)$ & 26.91 & 0.000 & 0.033 & Migrant > Local \\
\hline Social & $25.12(7.18)$ & $27.20(6.83)$ & 12.98 & 0.000 & 0.016 & Migrant > Local \\
\hline Intrinsic & $11.25(4.27)$ & $12.15(4.15)$ & 6.39 & 0.012 & 0.008 & Migrant > Local \\
\hline Organizational Commitment & $2.76(1.17)$ & $2.89(1.31)$ & 0.32 & 0.57 & 0.000 & No difference \\
\hline
\end{tabular}

The results found that migrant females had a higher satisfaction with extrinsic job rewards, social job rewards, and intrinsic job rewards than did local females. A possible explanation for this finding is that migrant female workers may have lower expectations than urbanites [42], experience better life and work conditions in their current settings compared to those in their hometowns [32], can enjoy an expanded social network in their current work [14], are able to send remittance to improve the financial situations of their families [15], and can reduce their dependence on their husbands [43]. While the findings of this study cannot demonstrate a causal relationship between these factors and the resultant outcomes, they do help to reshape the public's image of female migrant workers. For example, even though migrant workers usually do not enjoy the same benefits and opportunities as local workers, they generally feel grateful for their work experiences as they view their work as opportunities for fulfilling their materialistic and relationship needs and realizing their personal potentials [15].

Interestingly, after ruling out the effects of age, the results show that migrant females felt more gratification from different aspects of job rewards compared to their local counterparts. However, there were no significant differences in both job satisfaction and organizational commitment between the two groups. A possible explanation for these findings is that many of the younger migrant female worker participants have grown up during the Social Transition Era of mainland China [15]. Given that this population were raised in a growing economy and changing society, it is likely that these individuals found it easier to transition from rural to urban settings and thus may not hold as strong of a sense of gratitude as compared to their older counterparts. This younger group is thus able to experience a smoother acculturation process and is accustomed to the widespread pursuit of a higher quality of life as promoted by mass media [13]. Consequently, these individuals are likely to adopt the urban ideology of work and to set higher expectations for their own subjective wellbeing in the workplace, and therefore are more likely to feel discontent with their current jobs when there is a discrepancy between their expectations and perceived reality.

Lastly, there were no significant differences in organizational commitment between migrant and local workers. In view of this result, it becomes relevant to consider how after marriage and pregnancy, most migrant female workers tend to return to their hometowns to care for their newborns for a short period of time [44]. Eventually, they would leave their children and hometowns to return to the city to work in order to financially support their families [44]. The separation from their children and family is a likely source of intense negative emotions for these female workers, so many migrant female workers would eventually return to their hometowns to seek out job opportunities or even start their own businesses [45]. As a result, this intrinsic incentive may explain why there was no difference in organizational commitment between migrant and local female workers.

The present findings provide insight that could help companies and policy makers improve the lives of female factory workers, especially migrant workers. The findings on intrinsic job rewards highlights how today's migrant females have a unique set of vocational attitudes that companies should be aware of if they wish to address these workers' vocational and psychosocial needs. In addition to fulfilling the financial needs of laborers, companies should also invest 
more in equipping workers with career and life skills to help them set and achieve personal goals. Such an investment is worthwhile because female factory workers with higher educational levels, higher manual dexterity, and stronger work motivation can ultimately serve as a tremendous asset for companies [15].

Moreover, in recent years, the Chinese government has made significant efforts to improve the employment, social security, and medical insurance systems across the nation in order to better protect the rights of migrant workers. However, these workers still receive less welfare benefits compared to their urban counterparts, especially those who are under the present household registration system in China [46]. Nonetheless, migrant workers are comprising a new type of working class in society. They should be viewed as an asset to the growing economy and ever-changing society in China. Through the insights brought about by migrant workers, the central and local Chinese governments can better conceptualize the needs and problems that confront this group The government should therefore provide a platform for this growing class of workers to express their thoughts and concerns regarding their citizen rights, work experiences, and quality of life. Similarly, the government should also guide and supervise companies in implementing employment contracts and social security systems to better protect workers' welfare and benefits [46].

Finally, this exploratory study has some limitations. First, given that the study utilized a non-randomized sample, the generalizability of the findings should be interpreted with caution. Second, there are limitations in the extent to which a cross-sectional quantitative study can demonstrate the differences in migrant and local female laborers' work experiences.

\section{CONCLUSION}

In conclusion, female factory workers are forming a new working class that can put forth new perspectives that could pique positive industrial advancements and social transformations. Thus, they are an integral part of society [12], and there is a need for the creation of a constructive work environment to support and empower these laborers.

\section{REFERENCES}

[1] National Bureau of Statistics of China. (2018). An investigation report of peasant migrant workers 2017. National Bureau of Statistics of China [Online]. Available: http://www.stats.gov.cn/tjsj/zxfb/201804/t20180427_1596389.html

[2] National Bureau of Statistics of China. (2012). Number of employed persons in urban units at the year-end 2011, Guangdong Statistical Yearbook 2012. National Bureau of Statistics of China [Online]. Available:

http://www.gdstats.gov.cn/tjnj/2012/table/5/05-06.htm

[3] National Bureau of Statistics of China. (2012). Number of females employed in urban units at the year-end 2011, Guangdong Statistical Yearbook 2012. National Bureau of Statistics of China [Online]. Available: http://www.gdstats.gov.cn/tjnj/2012/table/5/05-09.htm

[4] M. R. Di Tommaso, L. Rubini, and E. Barbieri, Southern China: Industry, Development and Industrial Policy, $1^{\text {st }}$ Ed. New York, NY: Routledge, 2013.

[5] D. F. K. Wong, Y. L. Chang, and X. S. He, "Rural migrant workers in urban China: Living a marginalized life," Int. J. Soc. Welfare, vol. 16, no. 1, pp. 32-40, January 2007.
[6] K. D. Robert, "Chinese labor migration: Insights from Mexican undocumented migration to the United States," in Rural labor flows in China, L. A. West and Y. H. Zhao, Eds. Berkeley, CA: Institute of East Asian Studies, University of California - Berkeley, 2000, ch. 7, pp. 179-230.

[7] S. Tan, "The relationship between foreign enterprises, local governments, and women migrant workers in the Pearl River Delta," in Rural labor flows in China, L. A. West and Y. H. Zhao, Eds. Berkeley, CA: Institute of East Asian Studies, University of California Berkeley, 2000, ch. 11, pp. 292-309.

[8] W. Feng, X. J. Zuo, and D. C. Ruan, "Rural migrants in Shanghai: Living under the shadow of socialism," Int. Migr. Rev., vol. 36, no. 2, pp. 520-545, June 2002.

[9] J. F. Shen and Y. F. Huang, "The working and living space of the "floating population" in China," Asia Pac. Viewp, vol. 44, no. 1, pp 51-62, April 2003.

[10] J. Mou, J. Q. Cheng, S. M. Griffiths, S. Y. S. Wong, S. Hillier, and D. Zhang, "Internal migration and depressive symptoms among migrant factory workers in Shenzhen, China," J. Community Psychol., vol. 39, no. 2, pp. 212-230, March 2011.

[11] D. F. K. Wong and G. Leung, "The functions of social support in the mental health of male and female migrant workers in China," Health Soc. Work, vol. 33, no. 4, pp. 275-285, November 2008.

[12] N. Pun, Made in China: Women Factory Workers in a Global Workplace, Durham, NC: Duke University Press, 2005.

[13] T. Jacka, "Finding a place: Negotiations of modernization and globalization among rural women in Beijing," Crit. Asian Stud., vol. 37, no. 1, pp. 51-74, 2006.

[14] T. Jacka, Rural Women in Urban China: Gender, Migration, and Social Change, New York, NY: M. E. Sharpe, 2005.

[15] S. M. To and H. L. Tam, "Generational differences in work values, perceived job rewards, and job satisfaction of Chinese female migrant workers: Implications for social policy and social services," Soc. Indic. Res., vol. 118, no. 3, pp. 1315-1332, September 2014.

[16] K. A. Losocco and C. E. Bose, "Gender and job satisfaction in urban China: The early post-Mao period," Soc. Sci. Q., vol. 79, no. 1, pp. 91-109, March 1998.

[17] A. Newman and A. Z. Sheikh, "Organizational commitment in Chinese small- and medium-sized enterprises: The role of extrinsic, intrinsic and social rewards," Int. J. Hum. Resour. Man., vol. 23, no. 2, pp 349-367, January 2012.

[18] I. O. Williamson, M. F. Burnett, and K. M. Bartol, "The interactive effect of collectivism and organizational rewards on affective organizational commitment," Cross Cultural Management, vol. 16, no. 1, pp. 28-43, 2009.

[19] J. R. Hackman and E. E. Lawler, "Employee reactions to job characteristics," J. Appl. Psychol., vol. 55, no. 3, pp. 259-286, June 1971.

[20] R. K. Chiu, V. W. M. Luk, and T. L. P. Tang, "Retaining and motivating employees: Compensation preferences in Hong Kong and China," Pers. Rev., vol. 31, no. 4, pp. 402-431, 2002.

[21] C. S. Yu, G. S. Taylor, and W. Tung, "A cross-cultural comparison of work goals: The United States, Taiwan and the People's Republic of China," in Chinese Culture, Organizational Behavior and International Business Management, I. Alon and O. Shenkar, Eds. London, U. K.: Greenwood, 2003, ch. 11, pp. 169-186.

[22] Y. Y. Wang, "Emotional bonds with supervisor and co-workers: Relationship to organizational commitment in China's foreign invested companies," IJHRM, vol. 19, no. 5, pp. 916-931, May 2008.

[23] J. L. Bokemeier and W. B. Lacy, "Job values, rewards, and work conditions as factors in job satisfaction among men and women," Sociol. Q., vol. 28, no. 2, pp. 189-204, June 1987.

[24] A. L. Kalleberg, "Work values and job rewards: A theory of job satisfaction," Am. Sociol. Rev., vol. 42, no. 1, pp. 124-143, February 1977.

[25] A. P. Brief, Attitudes in and Around Organizations, Thousand Oaks, CA: Sage, 1998.

[26] I. Nielsen, R. Smyth, and Y. Liu, "The moderating effects of demographic factors and hukou status on job satisfaction-subjective well-being relationship in urban China," IJHRM, vol. 22, no. 6, pp. 1333-1350, March 2011

[27] J. Kickul, S. W. Lester, and E. Belgio, "Attitudinal and behavioral outcomes of psychological contract breach: A cross-cultural comparison of the United States and Hong Kong Chinese," Int. J. Cross Cult. Manag., vol. 4, no. 2, pp. 229-252, August 2004.

[28] G. Johns and J. Xie, "Perceptions of absence from work: People's Republic of China versus Canada," J. Appl. Psychol., vol. 83, no. 4, pp. 515-530, August 1983. 
[29] J. L. Xie and G. Johns, "Interactive effects of absence culture salience and group cohesiveness: A multi-level and cross-level analysis of work absenteeism in the Chinese context," J. Occup. Organ. Psychol., vol. 73, no. 1, pp. 31-52, March 2000.

[30] C. Q. Lu, O. L. Siu, and C. L. Cooper, "Managers' occupational stress in China: The role of self-efficacy," Pers. Individ. Dif., vol. 38, no. 3, pp. 569-578, February 2005.

[31] O. L. Siu, P. E. Spector, C. L. Cooper, L. Lu, and S. F. Yu, "Managerial stress in greater China: The direct and moderator effects of coping strategies and work locus of control," Appl. Psychol., vol. 51, no. 4, pp. 608-632, October 2002.

[32] S. H. Chan and H. H. Qiu, "Loneliness, job satisfaction, and organizational community of migrant workers: Empirical evidence from China," IJHRM, vol. 22, no.5, pp. 1109-1127, March 2011.

[33] I. Nielsen and R. Smyth, "Job satisfaction and response to incentives among China's urban workers," Working Paper Series 23/06, Dept. of Management, Monash University, Melbourne, AU, 2006.

[34] R. T. Mowday, R. M. Steers, and L. W. Porter, "The measurement of organization commitment," J. Vocav. Behav., vol. 14, no. 2, pp. 224-247, April 1979.

[35] X. Yu and N. Pun, "Walmartization, corporate social responsibility, and the labor standards of toy factories in South China," in Walmart in China, A. Chan, Ed. Ithaca, NY: Cornell University Press, 2011, pp. 54-70.

[36] D. F. K. Wong and Y. L. Chang, "Mental health of Chinese migrant workers in factories in Shenzhen, China: Effects of migration stress and social competence," Soc. Work Ment. Health, vol. 8, no. 4, 305-318, July 2010.

[37] C. J. Mottaz, "The relative importance of intrinsic and extrinsic rewards as determinants of work satisfaction," Sociol. Q., vol. 26, no. 3, pp. 365-385, 1985.

[38] A. L. Kalleberg, "Work values, job rewards and job satisfaction: A theory of the quality of work experience," Ph.D. dissertation, Dept. Sociology, University of Wisconsin, Madison, WI, 1975.

[39] Z. Cheng, "The new generation of migrant workers in urban China," in Urban China in the New Era: Market Reforms, Current State, and the
Road Forward, Z. Cheng, M. Wang, and J. Chen, Eds. Berlin, Heidelberg: Springer, 2014, pp. 125-153.

[40] S. M. To and H. L. Tam, "Work values, perceived job rewards and life outcomes of the new generation of Chinese migrant labourers' in Guangzhou, China: Implications for social work practice," Br. J. Soc. Work, vol. 46, no. 1, pp. 27-45, January 2016.

[41] W. Fang and S. S. Y. Ngai, "On the indigenization of social exclusion among young rural-urban migrant workers - The case of Hangzhou, a coastal city in China," Int. J. Adolesc. Youth, vol. 15, no. 3, pp. 193-216, 2009.

[42] I. Nielsen and R. Smyth, "Job satisfaction and response to incentives among China's urban workers," J. Socio. Econ., vol. 37, no. 5, pp. 1921-1936, October 2008.

[43] X. S. Feng, "The costs and benefits of rural-urban migration: A report on an inquiry conducted among rural women employed in the service, retail and other trades in Beijing," Social Sciences in China, vol. 18, no. 4, 52-65, 1997.

[44] S. M. To, Y. Y. So, and C. M. Kwok, "Meaning-making of motherhood among rural-to-urban migrant Chinese mothers of left-behind children," J. Child Fam. Stud., vol. 27, no. 10, pp. 3358-3370, October 2018.

[45] S. M. To, C. M. Lam, and Y. Y. So, "A qualitative analysis of rural-to-urban migrant Chinese mothers' experiences in mother-child interactions and self-evaluation," China Journal of Social Work.

[46] Z. K. Wang, "Social security for Chinese migrant workers," Int. Labour Rev., vol. 150, no. 1-2, pp. 177-197, June 2011.

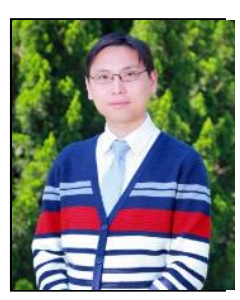

Siu-ming To is an associate professor of the Department of Social Work of The Chinese University of Hong Kong. He obtained the doctor of philosophy (social welfare) at the Chinese University of Hong Kong in 2006. His research interests are in the areas of life and career development of young people and disadvantaged youth, parenting and parent education, youth empowerment, and program evaluation. He has published more than 40 refereed journal articles. 